\title{
Identification and Management of Risks in Construction Projects
}

\author{
Mohammad Ali Rezvani Befrouei ${ }^{1,}$, Mohammad Taghipour ${ }^{2}$ \\ ${ }^{1}$ Department of Civil Engineering, Non-profit Institution of Higher Education, Aba - Abyek, Qazvin, Iran \\ ${ }^{2}$ Research Assistant of Non-profit Institution of Higher Education, Aba - Abyek, Qazvin, Iran
}

Email address:

Rezvanibefrouei@yahoo.com(M. A. R. Befrouei), mohamad.taghipour@srbiau.ac.ir (M. Taghipour)

\section{To cite this article:}

Mohammad Ali Rezvani Befrouei, Mohammad Taghipour. Identification and Management of Risks in Construction Projects. American Journal of Civil Engineering. Vol. 3, No. 5, 2015, pp. 170-177. doi: 10.11648/j.ajce.20150305.15

\begin{abstract}
Today, risk management in construction projects is considered to be a very important managerial process for achievement of project's objectives in terms of time, costs, quality, safety, and environmental sustainability. Instead of employing a systematic approach for identification of risks, their probability and their effects, most of the studies conducted in this area have focused only on a few aspects of risk management in construction project. However, the present study aims to identify and analyze the risks associated with development of construction in the greater city of Tehran, employing a comprehensive approach that is consisted of five aspects. In order to conduct this descriptive-analytical research, after studying, identification and categorization of different types of risks and preparing a relevant questionnaire, a number of 52 active construction companies from different areas have been randomly selected to be questioned about the impact of those risks on construction projects. After the collection and observation of the data, the output was examined by Pearson correlation also, using charts and tables. The results indicated that "tight project schedule" - present in all five categories- imposed the maximum risk. Also "design variations", "excessive approval procedures in administrative government departments" and "unsuitable construction program planning" were identified as next high risk factors.
\end{abstract}

Keywords: Risk, Risk Management, Construction Projects

\section{Introduction}

Risk management is one of the most important duties of project managers. If it's not recognized as a crucial responsibility, numerous problems will follow. Effective risk management requires the application of a systematic methodology, and more importantly, it requires knowledge and experience [Serpella, 2014].The main purpose of risk management in construction projects is to provide a safe work environment for the workers, and better achievement of goals. Findings reveal that risk management in construction projects has always faced defects and shortcomings which have had negative effects on the projects' efficiency [Cesarini, Hall, Kupiec, 2013].

For years, undermining risk management in construction projects has led to undesirable results and poor quality. For instance, management inefficiency and incorrect analysis of two important project factors, cost and time, which cannot be accurately determined, may lead to delay in the project and impose further costs. Today, the studies reveal the lack of systematic risk management methods in most of construction projects. The reason is that it has always been the people who adapted themselves to their work environment, and the adaptation of the work environment to the people has been undermined. This in turn will lead to negative consequences in implementation of projects. The statistics show that the vocational risk is an important factor preventing the realization of project goals in terms of time, costs, and quality. The purpose of this study is to identify different types of risks in construction projects, to analyze those risks and to improve the risk management by raising awareness and knowledge in all vocational levels involving the projects, and also to develop an efficient system of management based on the relevant knowledge, and consequently reducing the negative effects of the risks to come.

This approach is part of an attempt by an investigative research project whose primary results indicated that risk management in construction project is still suffering inadequacies; and the main reason for that is the contractors' and workers' lack of knowledge and awareness. It is expected that this study helps overcome the existing flaws and 
shortcomings and also improve the performance of project risk managers.

\section{Risk}

Risk is defined as a deviation from possible future events. If there is only one possible future event, then there is less chance of deviation and risk. We live in a world of risks and misadventures. Therefore the risks must be analyzed, and if encountered, must be identified and their consequences must be evaluated. Risk management is the process of documentation of the final decisions and implementation of the criteria that can minimize the risk to an acceptable level. In other words, it is the process of identification, evaluation, taking control measures and course corrections for the risks that would otherwise lead to further loss, or at least no change in the existing status.

Risk management is a systematic method of recognizing dangers and evaluating risks in order to provide required information to decide on appropriate risk reduction measures [Sehat\&Alavi, 2010]. Risk management enables a system to make better management of usual risks in its daily activity, and continue its activities more effectively and comprehensively in a stress free environment. It also enables us to reach acceptable results with minimal costs. Risk identification requires the recognition of links in a chain that include srisk factors, resources exposed to risk, and the effect of the first one on the latter. The purpose of risk identification is to collect information on the kind of damage to which the project at hand is exposed [Sehat \& Alavi, 2010]. This science presents methods and protocols that equip companies, organizations and governments with foresight and provisions to evaluate, control, and finance for future losses. On this basis, risk management arranges a systematic encounter with risks ahead. And for that purpose it is always faced with two fundamental questions about the future events. The first one is "what will happen?" and the second one is "what should be done?" Risk management is constantly planning ahead to encounter the possible future events.

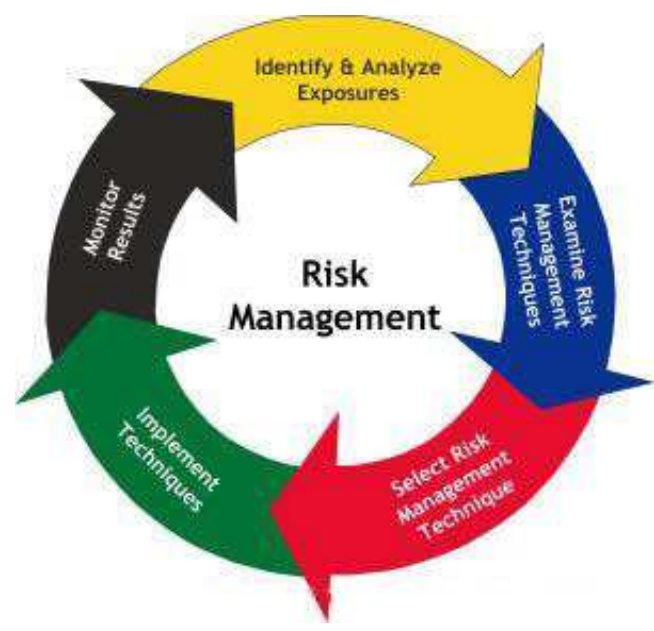

Picture 1. Risk management cycle.
According to the protocols presented by risk management, protecting organizations and investments from dangers and losses requires a system of thought and practice which integrates policies and regulations against risks. Such system is continuously investigating problems of the institutions at stake, and finding appropriate and effective resolutions. On this basis, the mentioned system must distinguish and define the existing problems and structurally analyze them; and by collection and classification of the relevant information, it must produce the best possible method for risk prevention and control.

Risk management operational cycle:

- Identification of problems (risks)

- Identification and explanation of the needs

- Structure analysis of the problems (risks)

- Collection and classification of information

- Devising a strategy for encountering the risks

- Supervision and follow-up

Main stages of risk management process:

- Defining the risk management objective

- Risk identification

- Risk assessment

- Preparing risk treatment plans

- Risk sharing/ transfer to another party such as insurance company

- Risk avoidance, and if necessary, risk reduction/prevention (Iran's I.T professional forum)

\section{Data Collection}

Risks in construction projects can be divided into five categories: cost risks, time risks, quality risks, environmental risks, and security risks. Each of the categories is consisted of 8 important risk factors, some of which, such as tight programming schedule and unsuitable construction program planning, are shared by all five categories; while some other risk factors are only shared by two or three of them. This study indicates to what extent each of these risk factors affect the execution of a project and achievement of its goals. In order to undertake this analytical-descriptive study, among different construction companies and contractors in Tehran, a number of 52 active companies were selected randomly; and using a questionnaire, the risk managers, employers, advisors and contractors were asked about the impact of the risks on construction projects. After collection and observation of the answers, the frequency of results was obtained by the use of charts and tables.

\subsection{Cost Factor}

Today, management of construction is faced with unpredicted situations in programming and construction of private and public accommodations to meet the demands of the society. Environmental control and other legal controls and regulations, energy consumption costs and energy accessibility, constant change in public taste and economic state, are among such problems. Some causes of delay and slow pace in projects are incorrect understanding of the 
project's size and volume, incorrect estimation of required resources, weak cost programming and budget assessment, incapability in control of project's performance costs, and in general, weakness in project's cost management. It is obvious that keeping up with the times, and employment of modern science and techniques, will ensure better management of project costs. Table 1 demonstrates the correlation between risk and the factors related to cost.

Table 1. The results of the Pearson correlation coefficient between risk and the factors related to cost.

\begin{tabular}{lll}
\hline Factors related to costs & $\begin{array}{l}\text { correlation } \\
\text { coefficient }\end{array}$ & $\begin{array}{l}\text { Significance } \\
\text { level }\end{array}$ \\
\hline $\begin{array}{l}\text { Project's tight programming schedule } \\
\text { Design variations and instability }\end{array}$ & $67 \%$ & 0.01 \\
$\begin{array}{l}\text { Inappropriate construction programming } \\
\text { Emergence of conflicts and disagreement }\end{array}$ & $52 \%$ & 0.01 \\
$\begin{array}{l}\text { Inflation and increase of construction } \\
\text { material prices }\end{array}$ & $65 \%$ & 0.01 \\
$\begin{array}{l}\text { excessive approval procedures in } \\
\text { administrative government departments } \\
\text { and municipality }\end{array}$ & $61 \%$ & 0.01 \\
$\begin{array}{l}\text { Incomplete or inappropriate cost } \\
\text { assessment }\end{array}$ & $64 \%$ & 0.01 \\
$\begin{array}{l}\text { Incorrect estimation of timing schedule } \\
\text { and project completion }\end{array}$ & $53 \%$ & 0.01 \\
\hline
\end{tabular}

As the data suggests, the risk of tight programming schedule with $67 \%$ has the most correlated and greatest impact, and after that, the risk of inflation and increase in construction material prices with $66 \%$, emergence of conflict and disagreement with $65 \%$, and excessive approval procedures in administrative government departments and municipality with $61 \%$ are next factors having great effects.

Budget imposes the primary limitation on all small or large-scale projects. Even in cultural projects, where people participate without receiving any payment, lack of human resources and lack of credit for preparation of requirements pose limitations. Project's budget planning is one the most important duties of project programmers and determining how to provide the required credit for development of project objectives is one of the project managers' difficult tasks, especially in large-scale projects where in addition to providing credits, the orderly arrangement of activities and determining their prerequisites play an important role in effective implementation of the project regarding the financial credits time tables. For instance, it's not wise to finish the base-course layout of a highway without providing credits for the asphalt layer and wait for the next year's budget. Because falling of rain and snow would damage the infrastructure and then a part of budget must be spent on base-course repairs. In scenarios like this, construction of the highway can be completed in separate segments, and those segments can eventually be interconnected. Budget and budget provision is an important element in project phasing and determination of the optimal size for each phase. Managers should obtain accurate information on the budget and project funders' financial commitment and share it with programmers; they should also accurately supervise budget receptions in order to prevent the costs increase in construction projects.

Therefore, cost estimation will be needed in to stages: first before the contract, in order to determine the suggested price, and secondly after the contract and during project execution for budgeting and cost control.

In fact, costs in construction projects can be controlled by taking certain courses of action mentioned below:

- Accurate estimations and special designs

- Application of project execution time control factor, which is directly related to cost control

- Correct and suitable financial management in construction projects

- Seizing opportunities to acquire financial resources

- Providing grounds for private section investment in project execution

- Participation of private section in non-financial investment in projects, in areas such as providing lands, materials, and other investments.

\subsection{Time Factor}

Another factor that plays the main role in achievement of goals in construction projects and in most of other projects as well is time factor. In fact, time management is the main principle of construction projects execution; and if neglected the project will fall into chaos and further costs will be imposed on the project. The greatest dilemma facing large-scale projects is the delay in completion of its various phases and consequently the delay in completion of the project itself. Delay is an action or occurrence that decelerates the execution of project and increases the prearranged duration of a certain action, which manifests as increased time-length of an activity or postponement of its start [Schumacher, 1995]. If a project's operation is delayed, national resources would be wasted and in some cases the project may lose its technical and economical plausibility [Vatankhah, 2003].

The discussion of construction projects' delay in economy council of Iran's organization of management and programming dates back to 1970, and it continues until present time; however it has not yet led to preparation of a legalized solution to this problem [Eshteahradian et al. 2010]. In a report published in 1971, organization of budget and programming divides the causes of delay into 4 categories:

Inaccuracy and mistakes in preliminary estimations

- Increase in task items or task volume, and execution technique

- Executive defects, problems and methods

- Other problems

It is apparent that many of the above mentioned problems are similar, if not identical, to those of present day construction industry in our country. This is a sign of lack of dynamism in the solution of executive problems of construction industry. It is interesting that according to the organization of budget and programming, $90 \%$ of construction projects have suffered from increase in 
duration and costs; and $60 \%$ of the unfinished projects need 15 years to complete [Shakeri\&Ghorbani, 2005]. It is necessary to mentioned that currently, the average time length of construction projects in Iran is 9 years, that is far off the standard time-length [Shakeri\& Ghorbani, 2005]. After the study of questionnaires in this research, the effect of risk factors related to time was evaluated. Table 2 demonstrates the correlation between risk and the factors related to time.

Table 2. The results of the Pearson correlation coefficient between risk and the factors related to time.

\begin{tabular}{lll}
\hline Factors related to time & $\begin{array}{l}\text { Correlation } \\
\text { Coefficient }\end{array}$ & $\begin{array}{l}\text { Significance } \\
\text { level }\end{array}$ \\
\hline Project's tight programming schedule & $57 \%$ & 0.01 \\
$\begin{array}{l}\text { Design variations and instability } \\
\text { Clients' demand to make alterations }\end{array}$ & $46 \%$ & 0.01 \\
$\begin{array}{l}\text { Excessive approval procedures in } \\
\text { government departments and municipality }\end{array}$ & $45 \%$ & 0.01 \\
$\begin{array}{l}\text { Unsuitable construction programming } \\
\text { Government bureaucracy }\end{array}$ & $44 \%$ & 0.01 \\
$\begin{array}{l}\text { High expectations of quality and } \\
\text { performance }\end{array}$ & $36 \%$ & 0.01 \\
Unsuitable construction programming & $34 \%$ & 0.01 \\
\hline
\end{tabular}

As the data suggests, tight programming schedule risk ranks first in terms of effect, and after that, risks of design variations and instability and excessive approval procedures in government departments and municipality with $46 \%$, have the highest ranking.

Several studies on the project's delay have been conducted some of which have tried to reduce the delay by use of different methods [Schumache, 1995]. Some other studies have focused on the project delays in a certain industry or in a certain country. Among such studies the following can be mentioned: "studying the causes of delay and cost increase in Nigeria's construction projects (Mansfield \& Doran, 1994), identifying the causes of delay in Lebanon's construction projects (Mezher, 2002), a study of large-scale projects in Saudi Arabia, development report of 164 construction projects and 28 highway construction projects in Jordan between 1996 to 1999, studying the causes of execution delay mentioned in organization of budget and programming report, effective factors of delay in airport construction projects in Iran."

Specialty, commitment and healthy management are the characteristics of successful project managers. A weak project manager does not think of a contractor as his executive assistant, but as a claimant who deserve a great deal of wrong-doing. Such managers believe it to be one of their positive capabilities to postpone project manifests and statements and creating havoc in the process of responding to contractor's demands. They cause the deceleration of project execution and its increasing costs [Ahmadijazzi, 2006]. After the observation of these studies it can be concluded that since projects main elements (employer, consultant, and contractor) play an important role in delaying the project, it is advised the this three element try to systematize project management and develop a procedural approach to management science in large-scale in order to achieve that goal.

\subsection{Quality Factor}

After time factor, the most important principle in of construction projects is the concern with quality, since low quality execution of construction projects causes the investments to go to waste; on the other hand increase in quality will lead to project durability, and prevents investment and financial waste. Also management of project safety will prevent possible damages.

Unfortunately even today there are some construction projects wherein technical principles are not observed and that leads to technical weak points in project execution. Also lack of continuous inspection by executive managers and supervisors allow the technicalities and construction principle to be overlooked, hence the industrial quality of the outcome is reduced. Table 3 demonstrates the correlation between risk and the factors related to quality.

Table 3. The results of the Pearson correlation coefficient between risk and the factors related to quality.

\begin{tabular}{lll}
\hline Risk factors related to quality & $\begin{array}{l}\text { Correlation } \\
\text { Coefficient }\end{array}$ & $\begin{array}{l}\text { Significance } \\
\text { level }\end{array}$ \\
\hline Tight programming schedule & $56 \%$ & 0.01 \\
Incorrect assessment of project's timetable & $41 \%$ & 0.01 \\
$\begin{array}{l}\text { Incorrect estimation of costs } \\
\text { Unqualified management of subsidiary }\end{array}$ & $39 \%$ & 0.01 \\
$\begin{array}{l}\text { contractors } \\
\text { High expectations of quality and }\end{array}$ & $36 \%$ & 0.01 \\
performance & $34 \%$ & 0.01 \\
$\begin{array}{l}\text { Lack of coordination between project } \\
\text { participants }\end{array}$ & $46 \%$ & 0.01 \\
$\begin{array}{l}\text { Lack of skilled workforce } \\
\text { Unsuitable construction programming }\end{array}$ & $42 \%$ & 0.01 \\
\hline
\end{tabular}

As demonstrated, the risk of tight programming schedule with $56 \%$ ranks first in terms of impact. And lack of coordination between project participants and lack of skilled workforce with $46 \%$ and $42 \%$ respectively, are the next risk factors in line in terms of impact. Also high expectation of quality and performance with $34 \%$ is an effective risk factor when it comes to construction project's quality, as well as an effective time risk factor.

Modern situation of organizations become more dynamic every day and present managers with new challenges. Universal competition and expectations of an evolving community always bring up new management requirements. Concepts such as participation, enabling, teamwork, flexibility and etc. are considered as an organization management's everyday concerns. Additionally, through efficient operation, employment of modern technology, and by commitment to produce high quality products and services for better satisfaction of customers and clients, new demands for efficiency and competitive advantages have emerged. Considering that, comprehensive quality management is one the most effective methods used in management systems to 
cover all issues related to quality.

Problems in construction quality, such as low quality of execution, lack of attention to workforce and human resources and costs of redoing urged the creation of a quality management system in this industry. Construction as an important industry, receive a great amount of states' budget, therefor, quality management in construction in order to ensure its continuance, supply the demands, avoid redoing, increase the employees' participation and encourage teamwork brings great profits [Harischian et al. 2007]

However it's not enough just to provide a high quality product and service that satisfies the taste of the client; costs of achieving this purpose must also be considered carefully. If the long-term effects of the costs for quality work on the company or organization are rendered as positive, such expenses are acceptable. One of the most important criteria in implementation of quality management systems is the correct understanding of quality costs (i.e. further costs that are imposed on the company because of lack of quality, or too high a quality). Considering its importance, identification of required resources for the project and accurate control and management of costs and analysis of quality costs seem crucial [Abbasnia\&Moradisangi, 2010].

Some criteria that can help improve the quality of construction projects are mentioned below:

- Implementation of a quality control team at worksites of major construction projects to examine the quality of concrete in terms of strength

- Making drastic changes in the structure and different aspects of project execution, including management, execution deployment, and contractor

- Direct connection of project design with policies that are sometimes made simultaneous to the execution of the project

- Avoiding wrong and experimental methods and employment of engineering science and improvement of project's scientific standards

- Employment of engineering wisdom and general knowledge along with experiences from previous construction projects

- Establishment of special departments inside civil construction staff, such as department of urban buildings and streets maintenance, project control unit, research and education unit etc.

\subsection{Environmental Factor}

Workplace is an environment that is prone to risks and dangers. It is necessary for the safety of workers in a construction area to establish order in workshops, collect rubbles and construction waste, and take precautionary measures to avoid falling down. Also adjacent buildings and urban areas must be taken into consideration.

Underground projects are closely related to geo-technique issues. For instance structure collapse must be taken seriously. Preventive measures in such project are taken in three stages:

- At the beginning of the project; short term
- During the operation of vibrating machines; medium term

- After the project and during revenue operation; long term

On this basis, a comprehensive project safety operation must be laid out and regulations must be established for project execution, repairs and maintenance, and periodical examinations.

According to the statistics, safety measures such as scaffolding to prevent people and material from falling are seriously significant in projects conducted in heights, such as high buildings, communication towers, television towers and etc.

Nocturnal jobs or working in dim lights, even in simple urban projects can lead to accidents. Hiring well-trained personnel does not increase costs as much as it prevents accidents and project stoppage or delays. Therefore in night time urban projects some individuals must be hired for the purpose of warning and protecting others. Table 4 demonstrates the correlation between risk and the factors related to environment.

Table 4. The results of the Pearson correlation coefficient between risk and the factors related to Environment.

\begin{tabular}{lll}
\hline Environmental risk factors & High & $\begin{array}{l}\text { Significance } \\
\text { level }\end{array}$ \\
\hline Tight programming schedule & $39 \%$ & 0.01 \\
Unqualified subsidiary contractor's manager & $24 \%$ & 0.01 \\
Client's demand for making alterations & $25 \%$ & 0.01 \\
Incorrect and inadequate information about & $35 \%$ & 0.01 \\
worksite (soil examination and analysis report) & $24 \%$ & 0.01 \\
High expectation of quality and performance & $22 \%$ & 0.01 \\
Unsuitable construction programming & $38 \%$ & 0.01 \\
Construction's severe noise pollution & $27 \%$ & 0.01 \\
Lack of professional staff and managers & & \\
\hline
\end{tabular}

As demonstrated, tight programming schedule risk with $39 \%$ has the highest impact. And sever noise pollution and inadequate information about the worksite (soil analysis and report) with $38 \%$ and $35 \%$ respectively, are next risk factors in terms of effectiveness. Also unsuitable construction programming and unqualified subsidiary contractor's management with $22 \%$ and $24 \%$ respectively, have the least impact between risk factors in construction projects.

\subsection{Safety Factor}

Before continuing the discussion, three elements of safety, accident, and danger need to be defined.

Safety: in the dictionaries, safety defined and security, peace, and health. It is defined and the level of being secure from risk or danger. In fact, the safety in construction projects is consisted of:

- Security and health of all the labor force and individuals related to construction projects environment

- Security and health of all the individuals who live or pass through adjacent areas of construction project environment (effective radius)

- Security and protection and monitoring of buildings, 
vehicles, structures and equipment inside the project's worksite or in adjacent areas

- Protection of living environment inside project's worksite and its adjacent areas

Accident is an unpredicted and mostly harmful incident caused by an unsafe action or unsafe situation -or a combination of both- which has negative influence on completion or natural continuation of a task or activity.

Danger is a condition which has the potential to harm employees, damage tools and equipment and buildings, destroy materials, or reduce the efficiency of a pre-organized action. It is the source or the potential cause of harm to individuals or organizational assets. Studies identify two major dangers in construction projects: danger of physical damage, and danger of diseases or health related issues [Savadkoohi, 2007].

Today, a lot of construction projects are being carried out in our country and a lot of people participate in those projects. It is obvious that this great population of human resources is exposed to a lot of dangers. Considering the sites in which these projects are being carried out, people and civilians of the neighboring areas are also threatened by these dangers. Most of these threats are caused by lack of safety knowledge or oversimplification of safety rules. The overwhelming amount of threats that would lead to damage and losses of lives and assets makes the evaluation of the impact of safety risk factors a crucial issue. Table 5 demonstrates the correlation between risk and the factors related to safety.

Table 5. The results of the Pearson correlation coefficient between risk and the factors related to Safety.

\begin{tabular}{lll}
\hline Safety risk factors & High & $\begin{array}{l}\text { Significance } \\
\text { level }\end{array}$ \\
\hline Tight programming schedule & $45 \%$ & 0.01 \\
Unqualified subsidiary contractors' management & $39 \%$ & 0.01 \\
Unsuitable construction management & $33 \%$ & 0.01 \\
Accidents and lack of safety regulations & $42 \%$ & 0.01 \\
observation & $26 \%$ & 0.01 \\
Lack of coordination between project participants & $28 \%$ & 0.01 \\
High expectation of quality and performance & $25 \%$ & 0.01 \\
Lack of skilled workforce & $25 \%$ & 0.01 \\
Lack professional managers and individuals & & \\
\hline
\end{tabular}

As demonstrated, risk of tight programming schedule has the greatest effect, and lack of safety regulation observation and unqualified subsidiary contractors' management with $42 \%$ and $39 \%$ respectively, are next risk factor in line in terms of effect. Also the risks of unsuitable construction programming and lack of skilled workforce with $33 \%$ and $25 \%$ respectively, have the least impact in safety of construction projects. Every year, a lot of accidents with irreparable consequences take place in construction projects and worksites only because of indifference toward safety rules. For that matter, implementation of safety regulation as a significant duty of different managerial and executive positions of construction projects is the only way to reduce accidents and losses. Although the chapter 12 of national construction regulations for safety and security is legally binding, still many safety rules are not observed and unfortunately numerous accidents still take place during construction projects.

To achieve desirable standards in construction safety, first social and cultural backgrounds are needed to be established in the community, and then, technical and executive infrastructures should be implemented in companies and organizations that are active in the field of construction. And finally, all levels and positions of construction projects, including employers, project managers, consultant engineers, and contractors must be educated and the technical knowledge must be shared with them. Apparently, this task requires special attention from high ranking managers of the industry, and a purposeful and objectified programming.

\section{Suggestions}

The first step toward workplace safety must be taken by executive positions; for the workers to take safety seriously, it must become an organizational virtue and value. In all levels of an organization, managers must establish the idea that safety is a responsibility embedded in their job description. In many cases, this responsibility is put upon a safety manager in worksite, or a security manager in organization. Executive project managers and supervisors are required to receive necessary educations in order to be able to encounter unpredicted conflicts, problems and accidents.

Active and credible companies usually use risk avoidance treatment; high level managers, safety managers and operatives create safety committees, discussing an analyzing performance safety to reduce -if not eliminate- risks and risk exposures. These committees must include operative employees, since through their field experience they can provide useful information and ideas on the appropriate ways to implement safety methods and better evaluation and improvement of safety. Although companies usually tend to employ safety managers only in large-scale projects, they need to do the same in small projects as well. Because workplace safety (whether in large or small projects) can prevent potential losses and damages, hence minimizing expenses. However, efforts for safety should not be limited to assignment of a safety manager. Safety managers should constantly supervise and evaluate performance of each individual, because, all the individuals are responsible for the safety of projects. When safety programs, procedures and routines are implemented from above, laborers will also take safety issues seriously. Safety and risk management programs must be assessed and approved on an annual basis, and managers' achievement in implementation of those programs must be evaluated. Companies also need to evaluate their success, by defining criteria such as "hours without accident" or achievement of a sensible annual rate of accidents. Only then they can claim that they have reached an optimal level of risk and crisis management [Alfredo, 2014]. Since a 
project is first programmed on a paper and on a theoretical basis, its safety and security must also be pre-programmed. A successful pre-program minimizes the threats that would delay a project, or reduce its efficiency, and allows the project to run smoothly.

\section{Conclusion}

In this research, after clear definition of risk, construction projects' risk factors have been analyzed using questionnaires distributed among organizations and institutions related to construction; and suggestions for better risk management in construction sites have been put forward. It must be noted that knowledge is the key element in successful risk management. A successful risk management requires application of appropriate methods, knowledge and experience such as prediction of accidents that might happen during project execution. Even when the project is running smoothly, lack of preventive measures could have negative consequences. The main issue concerning risk management is the avoidance of risks altogether; and preparation to overcome risks and problems in case they occur. However many companies refuse taking risk management measures because of their financial limitation, while their refusal would lead them to further costs and losses [Marras\&Karwowski, 2006]. It is fair to say risk management is an element of success in construction projects.

The project's success depends on an appropriate balance between three important issues of project's timetable, resources and results to present the client with a desirable service. The project serves to satisfy the client, therefore, these three elements must be balanced appropriately. Change in one element will lead to changes in the other two. For instance achievement of higher quality calls for increase in costs (and sometimes duration) of a project. To shorten the duration of project, either the final quality needs to be reduced, or the further costs need to be expended (i.e. more resources will be exhausted). Also with reduction of costs, the final quality will decrease and the project's timetable will become longer. Considering the importance of risks in urban projects, establishment of standards and protocols in such projects seem crucial. Such protocols must be established for all kinds of projects in general, and edited for specific projects in particular; and more importantly, the execution of these protocols must be accurately monitored.

Since procedural elements play an important role in risk preventions, they must be taken more seriously. Methods of project implementation must be determined with concerns for safety and security. Lack of professional considerations in compilation of executive methods is one of the main causes of accidents in construction projects. Education and justification of designers and executive engineers of the project is influential to project safety. Specifically in urban projects, special educational sessions need to be held. Employees' motivation and their demands have an important role in risk prevention and human resource efficiency therefor it must be taken into consideration by managers and engineers. In the end it must be noted that ever-increasing number of construction workshops call for serious supervisions by regulatory systems and organizations. Also emphasis on knowledge and awareness means education of employees and laborers before the start of project. As project programming should be carried out before the start of project, so is the education of employees for better risk management. Risk managers need to constantly evaluate employees and their performance. Also managers' participation will lead to individual commitment to safety. In the way to success, everyone is responsible; and responsibility is the main component in the culture of safety. Laborers, foremen, supervisors and managers are all responsible for the safety of project. The present study suggests that several elements, such as employees' work environment, project timing, tight programming, client's expectations, skilled workforce, and professional managers are taken into consideration in order to improve risk management in construction projects. Although it is still a matter of long debate, it is crucial to note that risk control and risk management is the best way to prevent possible losses and damages to qualitative and quantitative process of construction projects.

\section{References}

[1] Eshteharadian E, Nasrazadani S.M, Safavi S.A, Alikhani A. "studying the causes of delay in urban projects considering project's elements", $6^{\text {th }}$ international conference of project management, 2010.

[2] Ahmadi-jazzi R, "a study of the causes of delay in construction projects in Iran and its solutions", M.A thesis, Iran's science and technology university, 2006.

[3] "What is risk management", website of Iran's I.T. professional forum www.itpro.ir/.

[4] "Analytical report on the causes and solutions of construction projects' costs increase", organization of budget and programming.

[5] Savadkoohi F, “crisis management in urban-construction projects”, 2007.

[6] Shakeri E, Ghorbani A, "value engineering and management of conflicts and dispute in construction projects", $2 \mathrm{n}$ international conference of value engineering, 2005.

[7] Shakeri E, Ghorbani A, "project management and identification of the main claims and disputes of contractors", $2 \mathrm{n}$ international conference of value engineering, 2005.

[8] Sehat S, Alavi S.S, "the necessity of application of risk management to third party insurance, and the impact of new third party insurance laws on the related risks", Journal of Insurance world news No. 144 \& 145, 2010.

[9] Abbasnia R, Moradisangi V, "quality costs in construction projects", $6^{\text {th }}$ international conference of project management, 2010

[10] Vatankhah R, "a study of the causes of delay in construction projects of schools renewal organization", M.A thesis, Tarbiat Modarres university, 2003. 
[11] Harischian M, Moshtaridoost T, Rahimi-Aloughare I, "application of comprehensive quality management in improvement of construction projects' performance quality", $3^{\text {rd }}$ international conference of project management, 2007.

[12] Alfredo Federico Serpella, "Risk management in construction projects: a knowledge-basedapproach", 27th IPMA World Congress", 2014: 654.

[13] Cesarini, George; Hall, Geoffrey and Kupiec, Matthew; "Building a proactive safety culture in the construction industry", ACE USA, 2013.

[14] Kai Way LI and Cheng-Lung LEE, "Postural Analysis of Four Jobs on Two Building Construction Sites: an Experience of Using the OWAS Method in Taiwan", Journal of Occupational Health", 1999.
[15] N. Jaffar*, A. H. Abdul-Tharim, I. F. Mohd-Kamar, N. S. Lop, "A Literature Review of Ergonomics Risk Factors inConstruction Industry",Universiti Teknologi MARA Perak, Seri Iskandar, 32610 Perak, Malaysia, 2011.

[16] Marras W.S \& Karwowski W. Interventions, Controls, and Applications in Occupational Ergonomics. "The Occupational Ergonomics Handbook (2nd Edition) Taylor\&Francis", London, 2006.

[17] Mansfield, N. /Ugwu,O./Doran, T.," Causes of delay and cost overruns in Nigerian constructionptojects "International Journal of project management, 12 p. 254-260, nov1994.

[18] Mezher, Toufic / Jamali, Dima / Zreik, Carine, article, " The role of financial institutions in thesustainable development of Lebanon" May 2002. 